\title{
Author Correction: Illustrating human PLD
}

Lei Zheng and Guangwei Du (1)

Correction to: Nature Chemical Biology https://doi.org/10.1038/s41589-020-0503-3, published online 16 March 2020

In the version of this News and Views originally published, references 7 and 8 were swapped in the reference list. Reference 7 should be "Metrick, C. M. et al. Nat. Chem. Biol. https://doi.org/10.1038/s41589-019-0458-4 (2020)" and reference 8 should be "Bowling, F. Z. et al. Nat. Chem. Biol. https://doi.org/10.1038/s41589-020-0499-8 (2020). The error has been corrected in the HTML and PDF versions of the paper.

Published online: 31 March 2020

https://doi.org/10.1038/s41589-020-0527-8

() Springer Nature America, Inc. 2020 